\title{
La paridad postergada: resultados para las mujeres en las elecciones seccionales 2014 del Ecuador
}

\section{Gender Parity Postponed: Results for Women in Ecuador's 2014 Subnational Elections}

\section{María Arboleda}

Recepción: 14 de agosto de 2014 Aceptación: 30 de agosto de 2014

\section{Resumen}

Este artículo analiza la participación de las mujeres ecuatorianas en los sufragios seccionales del 23 de febrero de 2014. Presenta una contextualización histórica de las luchas de las mujeres por la igualdad en la política; una descripción del sistema electoral ecuatoriano en relación con la paridad; traza el panorama de resultados para las mujeres tanto en calidad de candidatas como de electas; revisa los efectos para las mujeres de las circunscripciones electorales según su tamaño y según el encabezamiento masculino de listas, tanto a nivel urbano como rural; incluye un análisis exploratorio del comportamiento electoral de mujeres y hombres en 5 casos de mujeres electas.

Palabras clave: candidatas, electas, cuotas, paridad, elecciones 2014.

\section{Abstract}

This article analyzes the participation of women in the 2014 subnational elections of Ecuador. It presents a historical contextualization of women's struggles for equality in politics; it describes the Ecuadorian electoral system in relation to parity; it traces the array of outcomes for women, both as candidates and as elected officials; it reviews the impact of electoral districts on women's access according to district size and male headed lists in both urban and rural levels; it includes an exploratory analysis of electoral turnout in 5 cases where women were elected.

Keywords: candidates, elected women, quotas, parity, 2014 elections. 


\section{Introducción}

T as elecciones seccionales de febrero de 2014 constituyeron el segundo proceso electoral realizado en el país bajo las normas de la nueva Constitución de 2008 y con la vigencia de la Ley Orgánica Electoral y de Organizaciones Políticas de la República del Ecuador, Código de la Democracia (2009). La nueva Constitución de la República introdujo el principio de igualdad (artículo 11), por el cual todas las personas son iguales y gozan de los mismos derechos, deberes y oportunidades y nadie puede ser discriminado por razón de sexo, identidad de género, identidad cultural, entre otros atributos identitarios. Los principios de paridad y alternancia en la conformación de la autoridad pública también constan en la Constitución de 2008, los cuales también fueron recogidos en el Código de la Democracia.

Según este marco constitucional y legal, las candidaturas presentadas a los sufragios de febrero deberían cumplir con el 50 \% de integración de mujeres de manera alternada y secuencial. Sin embargo, las candidatas representaron tan solo el $42,1 \%$ del total mostrando una diferencia de casi 16 puntos $(15,8 \%)$ respecto de los candidatos, una brecha en la entrada del proceso electoral que afecta las oportunidades de las mujeres. Los resultados son aún más preocupantes puesto que apenas un $25,4 \%$ de mujeres fueron electas mientras el 74,6\% de dignidades continúan ocupadas por hombres. Aún más, si se pone en relación el porcentaje de mujeres electas $(25,4 \%)$, con el porcentaje de candidatas (42\%), se abren interrogantes sobre cómo acercar la igualdad y la participación de las mujeres en las estructuras de representación y gobierno de nuestro país, desde los mecanismos mismos del sistema electoral.

En busca de analizar estos temas, el texto se organiza en tres acápites. En el primero se presenta una contextualización histórica de las luchas de las mujeres por la igualdad en la política, una revisión de la literatura sobre la discriminación de las mujeres en cuanto a sus derechos políticos, una descripción del sistema electoral ecuatoriano en relación con la paridad 
y una síntesis metodológica. El segundo acápite traza el panorama de resultados para las mujeres tanto en calidad de candidatas como de electas y revisa los efectos, para las mujeres, de las circunscripciones electorales según su tamaño y según el encabezamiento de listas, tanto a nivel urbano como rural. Se incluye un análisis exploratorio del comportamiento electoral de mujeres y hombres en 5 casos de mujeres electas (2 prefectas y 3 alcaldesas). En el tercer acápite se resumen las conclusiones.

\section{Las ecuatorianas y el derecho al sufragio}

El interés de las ecuatorianas por participar en la esfera política ha sido documentado desde fines del siglo XIX y en las primeras décadas del $\mathrm{XX}$, cuando el tema del sufragio femenino se convirtió en uno de los ejes del debate social. En esta época, numerosas mujeres adscribieron al ideario liberal y participaron en luchas por sus derechos civiles y políticos, fenómeno que - como afirma Ana María Goetschel (2009)produjo "un campo de fuerzas en el que cumplieron un rol activo las mujeres". Sin embargo, aunque la Constitución Liberal de 1897 levantó la prohibición del voto femenino para las mujeres alfabetas y la Constitución de 1906 tampoco incluía ninguna disposición contra el voto femenino, era usual, afirma la autora, que las mujeres no votaran: el peso de los patrones culturales tradicionales naturalizaba el no acceso femenino al sufragio y volvía normal su condición de no-ciudadanas.

Rodas (2000, citada por Ayala, 2008), ha documentado cómo en 1924, con ocasión de las elecciones para senadores y diputados, Matilde Hidalgo solicitó su inscripción como votante en una Junta Electoral en Machala. La demanda tomó cinco años de deliberaciones hasta que el Congreso de la República promulgó el derecho de las mujeres al voto en 1929. ${ }^{1}$ Ecuador fue, gracias a ello, el primer país de América Latina en

1 Matilde Hildalgo se convertiría en la primera concejala municipal electa en el país -entre 1938 y 1940 - y en la primera diputada electa en 1941. Fue también la primera ecuatoriana en acceder al título de Bachiller de la República y la primera en graduarse con un título universitario (Doctora en Medicina) en 1921 (Rodas, Raquel: 2000, citada por Ayala Marín: 2008). 
reconocer el sufragio femenino. Según Goetschel, la acción de Matilde Hidalgo no fue aislada: se inscribió en un elenco de acciones que las mujeres venían sosteniendo en la esfera pública.

En los años 30, sectores conservadores promovieron el sufragio femenino al interior de sus tendencias políticas. De otra mano, inmersos en una herencia radical y laica, diversos grupos de mujeres activaron en la vida pública. En 1938, la primera organización política de mujeres, la Asociación Femenina Ecuatoriana o AFE, de destacada actuación en la insurrección popular de 1944 conocida como La Gloriosa, demandó la “igualdad de derechos económicos, sociales y políticos para todos los ecuatorianos”, con énfasis en las mujeres. La nueva Constitución de 1945 consagró derechos para ellas, como libertad para disponer de bienes y protección para su trabajo. Muchas de estas normas serán desconocidas en años posteriores.

Estas luchas entrarán en una nueva fase en los años 80s, cuando en América Latina se reposiciona el debate sobre la participación de las mujeres en la política. En Ecuador, tras el retorno a la democracia, un equipo de investigadoras/es realizó un estudio exploratorio sobre el voto femenino en Quito (Rojo et al: 1984). El estudio analizó los estereotipos y discursos sobre las formas de adhesión política y de votación de las quiteñas, resaltó la importancia de las mesas de votantes separadas por sexo, de la desagregación por sexo en los registros electorales y revisó los discursos de las organizaciones políticas hacia las votantes. Las investigadoras encontraron "(...) un electorado femenino estable" y un "alto grado de consistencia en las votaciones (que) muestran que las mujeres están imbricadas en la dinámica política del país" (Rojo et al: 1984, 87).

Diez años después, en 1995, las organizaciones de mujeres posicionan una agenda que incluyó una demanda por cuotas y paridad. La tesis surgió también por otras fuentes. En 1997, el Partido Roldosista Ecuatoriano (PRE), interesado en fortalecer la adhesión de mujeres, presentó la primera norma sobre cuotas del país: una Ley de Amparo Laboral de la Mujer que dispuso la inclusión de un 20\% de mujeres como candidatas. Ecuador se convirtió así en el primer país del área 
andina en establecer una cuota electoral y de inclusión de mujeres en espacios públicos y en la producción (Vega, 2004; Goyes, 2008).

En 1998, con la instalación de una Asamblea Constitucional, el movimiento de mujeres incidió ante el grupo de asambleístas electas y la nueva Constitución, en su artículo 102, consagró el derecho de las mujeres a participar en equidad con los varones como candidatas en procesos electorales (Rosero, 2000). Dos ańos después, la nueva Ley Orgánica de Elecciones incorporó todas las normas relativas a la participación política de las mujeres ${ }^{2}$, constituyendo un corpus de medidas afirmativas cuyo horizonte era la paridad. Se partió de la inclusión de un 30\% de mujeres en las listas, en cargos principales y suplentes, aplicando la fórmula cremallera, es decir en forma alternada y secuencial. La cuota debía incrementarse cada proceso electoral en un 5\% hasta llegar a la paridad (Rosero: 2000; Goyes: 2008). Exigir el cumplimiento de estas normas, como ha documentado Goyes, "se convirtió en bandera de lucha del Movimiento de Mujeres". Esta normativa, a la época, fue "considerada una de las mejor logradas en comparación con sus similares de América Latina”.

El año 2007, mediante una convocatoria que garantizó la paridad, se presentó un 48,79\% de candidatas a la Asamblea Constituyente. De ellas, 33,8\% fueron electas asambleístas, el porcentaje más alto obtenido hasta la actualidad en esta dignidad. La nueva Constitución de 2008, en su artículo 116, ratificó la paridad y la alternancia disponiendo que el sistema electoral la garantice y evite la vulneración de este principio (CNE, s.f.:12). Ecuador se convirtió de esta manera en uno de los cuatro primeros países de América Latina en establecer una norma de paridad junto a Bolivia, Costa Rica y Nicaragua. ${ }^{3}$ La nueva Constitución (artículos 11, 66 -numeral 4- y 65), reconoce también la igualdad formal y material y las establece como base de la no discriminación por razones de sexo, identidad sexual o pertenencia de género. Goyes explica el espíritu integral de la norma como:

2 Artículos 8, 58, 59, 60, 61, 68, 83 y 170, Ley de Elecciones, Registro Oficial No. 117 del 2000.

3 A ellos hay que sumar Panamá que aprobó la paridad en 2014 y México que la legisló aunque no para todos los niveles de elección. 
“....fin y medio para democratizar la sociedad, (que...) plantea un horizonte de transformación de las relaciones entre ciudadanos y ciudadanas; está íntimamente relacionada con el principio de igualdad real y el deber de corresponsabilidad entre hombres y mujeres en las tareas públicas y privadas, elementos que, en conjunto, revelan un esfuerzo por cimentar un nuevo modelo de convivencia cuyos dispositivos apuntan a deconstruir el sistema patriarcal que, por siglos, ha mantenido a las mujeres alejadas del espacio público" (Goyes, 2013: 38).

\section{Marco conceptual}

La exclusión de las mujeres de la política es una de las dimensiones que informan los procesos de transformación que se viven en Ecuador en las dos últimas décadas. Si bien esta exclusión -al igual que en otras latitudes-- proviene y se ancla en estructuras y patrones históricos (Astelarra, 1992), el aporte de Fraser ha permitido reconocer que tiñe los modernos sistemas de representación y democracia. La ciencia política, de manera general, reconoce que la permanencia de este estado de cosas es parte de relaciones asimétricas y jerárquicas de poder entre hombres y mujeres y usa la noción de comportamientos tradicionales o conservadores por causa de género para aquellos que buscan mantenerlo, mientras caracteriza como comportamientos no tradicionales los que promueven un cambio hacia una multiplicidad de otras posibles interacciones políticas, sociales y éticas entre los géneros (Matos et al, 2012).

Fraser (2006, citada en Gil Martín, 2011: 109), direccionando la necesidad de reformar las instituciones públicas con normativas de justicia, propuso la noción de paridad participativa, con la cual promovió la inclusión e igualdad de los subalternos frente a lo que llamó públicos dominantes. Fraser introdujo posteriormente la categoría representación errada (misrepresentation), para señalar los déficits de participación política que afectan a colectivos que sufren invisibilización o negación en los sistemas democráticos, como las mujeres o los indígenas e incluyó a la representación como el tercer campo de su propuesta 
de justicia, pensándola con un papel central de articulación y eficacia respecto de los otros dos, a saber, la necesidad de redistribución (económica) y de reconocimiento o estatus (Gil Martín, 2011: 120-122).

Hoy se acepta ampliamente que, como planteó Pitkin (1967, citada en Lombardo, 2008), las instituciones democráticas pueden y deben reflejar la población diferenciada por sexos realmente existente (representación en espejo), tesis concretada en la demanda de paridad y en una estrategia de cuotas electorales para acercarse a la misma. ${ }^{4}$ Las más diversas autoras conciben las cuotas y la paridad como mecanismos de reparación y justicia enmarcados en un enfoque de igualdad de oportunidades que se orienta a modificar brechas ${ }^{5}$ y eliminar barreras que afecten los derechos de las mujeres en la participación electoral. Esta afirmación tiene gran importancia para las mujeres puesto que ellas, como señalan Speck y Sacchet (2012), cuando entran al proceso electoral "no son páginas en blanco" y si bien las mujeres cuentan actualmente con atributos acumulados desde sus caminos de emancipación, aún deben enfrentar discriminaciones en muchas otras áreas.

Alves (2012) y Feitosa (2012) han mostrado que un conjunto de pautas o patrones de género preexistentes inciden en la eficacia de las normas y en los sistemas electorales incluso cuando éstos incorporan directrices de cuotas o de paridad, lo que resulta en que las mujeres concurran a las urnas en condiciones de desventaja respecto de los hombres. Por ello, si en su sentido más amplio la representación política de género responde a múltiples factores sociales, culturales, económicos, tanto estructurales cuanto superestructurales, también se performa con los mecanismos que definen la arquitectura de los sistemas electorales, los que pueden representar oportunidades o barreras para una participación femenina en igualdad (Feitosa, 2012: 165). En esto coinciden con Nohlen (2013: 3; 2012: 75), para quien los sistemas electorales, en

4 Existen al menos dos formas de cuotas. Las cuotas para mujeres establecen porcentajes mínimos de participación de mujeres como candidatas. Las cuotas de género establecen porcentajes máximos para cada sexo.

5 Brecha de Género es la "diferencia entre las tasas masculina y femenina en la categoría de una variable” (Instituto Andaluz de la Mujer, Indicadores de Género). 
tanto estructuras complejas que determinan las reglas con que los votos se convierten en cargos ejecutivos o escaños parlamentarios, pueden generar efectos en los sufragios y en sus resultados, por lo que recomienda rediseñarlos de acuerdo con las circunstancias y objetivos concretos.

Si los mecanismos señalados tienen impacto sobre la paridad, parecería necesario pensar al sistema electoral como una construcción perfectible a la cual es posible aplicar una perspectiva contrafáctica ${ }^{6}$ de género para promover nuevos condicionantes que contribuyan a modificar las desigualdades que afectan a las mujeres. Según la literatura revisada, al menos cinco mecanismos deben ser analizados en el sistema electoral ecuatoriano en relación con el objetivo de promover la paridad: el tamaño de las circunscripciones electorales, el número de escaños par o impar, el encabezado de listas con primacía masculina, la forma de voto para dignidades uninominales (y en binomio), y la forma de lista (abiertas, cerradas no bloqueadas y bloqueadas). A continuación describimos el sistema electoral ecuatoriano de cara a situar algunos mecanismos que pueden constituir barreras para las mujeres en la búsqueda de paridad.

\section{Sistema electoral ecuatoriano y mecanismos de paridad}

Ecuador elige un elenco de dignidades nacionales y locales, las cuales son de dos tipos: uninominales y plurinominales. A nivel local, las dignidades uninominales corresponden a prefectos/viceprefectos y alcaldes. Los cargos legislativos municipales (concejales urbanos y rurales) y las vocalías de las juntas parroquiales rurales corresponden en cambio a las dignidades plurinominales. ${ }^{7}$

Solo una de las dos dignidades uninominales locales, cuya elección se realiza mediante tres modalidades diferentes, permite aplicar las normas de paridad y alternancia: es la modalidad uninominal en binomio

6 "Los parámetros de opción son, sin lugar a duda, los supuestos o probables efectos de los sistemas electorales" (Nohlen, 2012: 75).

7 El cuerpo legislativo provincial, por disposición constitucional (artículo 252), se elige mediante representación indirecta de alcaldes, concejales y vocales de juntas parroquiales. 
con la que se elige el par prefecto - viceprefecta o viceversa, que cumple de manera obligatoria las normas de paridad y alternancia (artículo 163 del Código de la Democracia). La modalidad uninominal de alcaldes o alcaldesas no permite la aplicación de las normas de paridad.

En cuanto a su estructura, el sistema electoral ecuatoriano posee cuatro componentes: 1) forma de voto; 2) forma de lista (candidaturas); (3) método de asignación de escaños y (4) circunscripciones electorales. La forma de voto o manera en que el elector/a puede marcar su opción en la papeleta está asociada a la forma de lista. Nuestro país cuenta con voto personalizado múltiple, mecanismo que permite a la persona sufragante optar por una sola lista o entre listas (artículo 120, Código de la Democracia; esto indica que, a su vez, la forma de lista es abierta. El método para decidir los ganadores a dignidades uninominales es la mayoría absoluta, mientras en las dignidades pluripersonales se aplica la fórmula proporcional, con la que se adjudican escaños según el porcentaje de votos que obtienen los candidatos. ${ }^{8}$

Las circunscripciones electorales, en cambio, se definen según tipo y tamaño. El tipo refiere al territorio: la circunscripción puede coincidir con el territorio del país, con la división político-administrativa o ser creada ex profeso con fines electorales. En 2014, el CNE, cumpliendo con el artículo 118 de la Constitución y con el artículo 150 del Código de la Democracia, aplicó por primera vez la distritación para la elección de alcaldes y concejales en 13 municipios incluyendo el Distrito Metropolitano de Quito. Esto se sumó a las circunscripciones de orden provincial, cantonal, municipales urbanas y rurales y las de parroquias rurales previamente existentes.

El tamaño, por su parte, está determinado por el número de escaños que se adjudican en cada circunscripción y éstos se definen de acuerdo con la población. En nuestro país, un número impar de escaños prima en todas las dignidades, con la única excepción del binomio prefecto/a - viceprefecto/a. Ver tabla siguiente.

8 El procedimiento vigente en el país es el método D'Hondt, cuyos divisores continuos impares (1, 2, 3, 4, 5, etc.) producen cocientes decrecientes para cada partido (CNE, 2012: 12 - 14). 
Tabla 1.

Circunscripciones, número de escaños y aplicación de paridad

\begin{tabular}{|c|c|c|c|}
\hline Dignidad & Circunscripción & $\begin{array}{l}\text { Escaños de } \\
\text { población }\end{array}$ & $\begin{array}{c}\text { Paridad / } \\
\text { Alternancia }\end{array}$ \\
\hline $\begin{array}{c}\text { Prefecto/a - } \\
\text { Viceprefecto/a }\end{array}$ & Provincial & 2 (Binomio) & Aplica \\
\hline Alcalde/sa & $\begin{array}{l}\text { Cantonal y Distri- } \\
\text { to Metropolitano }\end{array}$ & 1 & No aplica \\
\hline Concejales/as & $\begin{array}{l}\text { Circunscripciones } \\
\text { urbanas y rurales }\end{array}$ & $\begin{array}{l}25 \text { (más de } 3 \text { millones de habi- } \\
\text { tantes) } \\
21 \text { (más de } 2 \text { millones de habi- } \\
\text { tantes) } \\
19 \text { (más de } 1 \text { millón de habi- } \\
\text { tantes) } \\
15 \text { (más de } 400000 \text { habitantes) } \\
13 \text { (más de } 300000 \text { habitantes) } \\
11 \text { (más de } 200000 \text { habitantes) } \\
9 \text { (más de } 100000 \text { habitantes) } \\
7 \text { (más de } 50000 \text { habitantes) } \\
5 \text { (menos de } 50000 \text { habitantes) }\end{array}$ & Aplica \\
\hline $\begin{array}{c}\text { Vocales de Jun- } \\
\text { tas Parroquiales } \\
\text { Rurales }\end{array}$ & Parroquia rural & $\begin{array}{l}7 \text { (más de } 50000 \text { habitantes) } \\
5 \text { (hasta } 50000 \text { habitantes) }\end{array}$ & Aplica \\
\hline
\end{tabular}

Fuente: CNE, s.f., $11-16$

Re-elaboración: María Arboleda

El impacto del tamaño de las circunscripciones electorales en las oportunidades de elección de las mujeres, en una relación directa (a mayor tamaño de la circunscripción, mayores chances para ellas) ha sido remarcada por algunos autores. Nohlen, sintetizando aprendizajes de la experiencia, afirma que el tamaño "puede ejercer influencia decisiva sobre la representación política (...)" puesto que en las circunscripciones pequeńas, "el porcentaje de votos que necesita un partido para obtener un escańo es matemáticamente tanto mayor cuanto menor sea el número de escaños que se adjudique" (2012: 8). Si parafraseamos esta última afirmación en relación con las mujeres, se puede pensar que en sistemas electorales que usan la fórmula proporcional, debido a la elevación de 
la cuota de proporcionalidad en las pequeñas circunscripciones, ellas necesitan más votos para obtener uno de los muy disputados escaños.

La integración de las circunscripciones con un número impar de escaños afecta también el número de candidatas presentadas debido a la práctica tradicional de encabezar las listas con candidatos hombres. Así, cualquier lista impar con encabezado masculino, conducirá irremediablemente a un número menor de candidatas ganadoras. El encabezado masculino en listas pares, aunque arroja un número igual de candidatos y candidatas, conlleva la práctica de subalternización de las mujeres al colocarlas persistentemente en el segundo lugar, lo que en términos electorales, genera menores oportunidades de elección y de recursos de competencia electoral (por ejemplo, ser convocado/ a entrevistas en los medios, etc.). El dominio masculino en la disputa electoral se expresa muchas veces, como ha sido documentado, en el uso de mujeres como relleno, lo que a sus vez sostiene la persistencia del encabezado con candidatos.

\section{Metodología}

Este trabajo realiza un análisis de tipo cuantitativo y cualitativo inscrito en los enfoques empírico tanto como normativo, para organizar un cuadro descriptivo del escenario creado en torno a las elecciones seccionales de 2014, en relación con los resultados que las mujeres obtuvieron en ellas y de cara a dilucidar algunos efectos de género derivados de la aplicación de los componentes del sistema electoral vigente, combinados con prácticas tradicionales de comportamiento político como, por ejemplo, la primacía masculina en el encabezado de listas.

A partir de fuentes estadísticas oficiales provistas por el Instituto de la Democracia (IDD) del CNE, se seleccionó un pequeño número de variables, que incluyen, por un lado, los porcentajes de mujeres empadronadas y sufragantes y los porcentajes de mujeres candidatizadas y electas. Se han realizado cruces de territorios (provincial, municipal y parroquial) de acuerdo con el elenco de dignidades a elegir. A ello se ańadieron, por un lado, la variable electas por ciudades capitales de provincia, debido al 
peso demográfico de las áreas urbanas del país. Para el caso de Galápagos, por la carga poblacional de la ciudad de Santa Cruz, se la incluyó en esta variable en lugar de la capital jurisdiccional. Por otro lado, se usó un cruce desde la variable edad y sexo, debido a la existencia del voto facultativo para los y las ciudadanas entre 16 y 18 años, buscando contar con indicios sobre la participación de las mujeres jóvenes.

En relación con los mecanismos electorales y su impacto en la candidatización y elección de mujeres y en torno al objetivo de promover la paridad de género en la representación política, se integró la variable tamaño de las circunscripciones electorales (mediana, pequeńa y única). Para vincular comportamientos electorales de género y resultados para las mujeres, se ha usado la variable encabezado masculino femenino de las listas. En ambos casos, estas variables fueron cruzadas por las dimensiones áreas urbanas y rurales.

De manera exploratoria, se realizó además un análisis sobre el comportamiento electoral de mujeres y hombres sufragantes en 5 casos de mujeres electas, seleccionados con el aporte del Instituto de la Democracia del CNE. Estos casos corresponden a las 2 únicas mujeres electas prefectas en Esmeraldas y Orellana, así como a 3 mujeres alcaldesas electas en Sierra, Costa y Amazonía (ninguna mujer fue electa a esta dignidad en Galápagos). Las ciudades escogidas corresponden a las de mayor población gobernada por una alcaldesa: Durán, Catamayo y Francisco de Orellana. Aunque la ciencia política remarca que los procesos de disputa electoral están fuertemente influenciados por factores externos al proceso de sufragio, advertimos que esta indagación exploratoria remite únicamente a los resultados de mesas electorales, haciendo abstracción de otros factores que pueden haber influido en el comportamiento electoral de mujeres y hombres, de los cuales no se cuenta con información o estudios. 


\section{Las ecuatorianas como candidatas}

Brecha de género en la entrada del proceso

Las elecciones seccionales constituyen los comicios de más amplia representatividad democrática del país, en términos del número de postulantes y los cargos en disputa. Un total de 28180 candidatos y candidatas principales se presentaron en febrero, de los cuales 16 317 (57,9\%), fueron candidaturas masculinas, mientras solo 11863 $(42,1 \%)$, fueron candidaturas de mujeres. Estos datos muestran que, pese a las normas constitucionales y legales, la paridad no se cumple en la candidatización femenina y que la diferencia de casi 16 puntos $(15,8 \%)$ entre candidatos hombres y mujeres revela la existencia de una notable brecha en la entrada del proceso electoral, en desmedro de la igualdad de oportunidades para las mujeres.

\section{Gráfico 1.}

Hombres y mujeres candidatos/as a nivel nacional (\%)

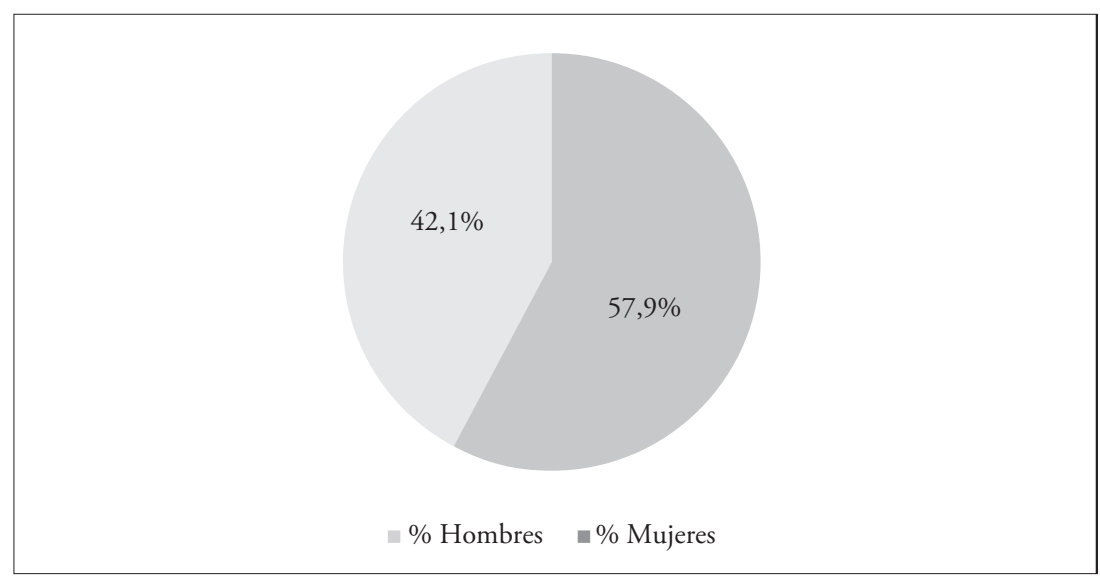

Fuente: CNE, Elecciones 2014

Elaboración: P. Jaramillo 


\section{Alcaldías y prefecturas: ausencia de candidatas}

Las brechas más significativas ocurrieron para los cargos de alcaldías y prefecturas. La candidatización masculina para prefectos subió al $86,2 \%$ con solo un $13,8 \%$ de mujeres corriendo para el mismo cargo. Peor aún, el porcentaje de hombres candidatizados para alcaldes fue de $87,8 \%$ con apenas un $12,2 \%$ de mujeres en la misma posición.

\section{Gráfico 2.}

\section{Candidatos principales por sexo y dignidad}

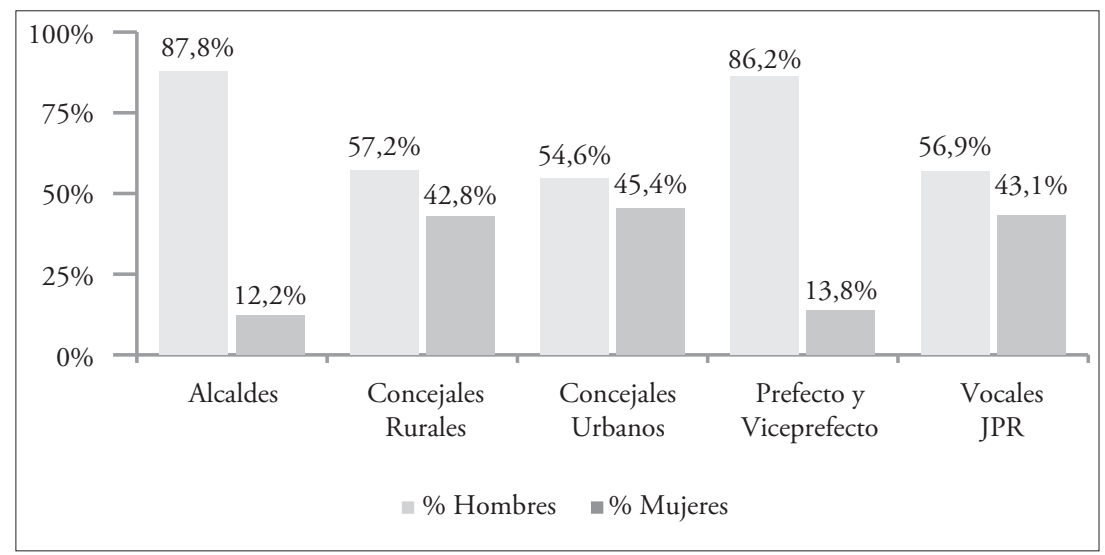

Fuente: CNE, Elecciones 2014

Elaboración: P. Jaramillo

Como hemos señalado en el acápite que describe el sistema electoral ecuatoriano, la candidatización de prefecto/a - viceprefecto/a y la de alcaldías difieren, por su forma de integración, en la aplicación de las normas de paridad. En la primera, configurada como uninominal en binomio y con la que se eligen conjuntamente dos autoridades, se aplica obligatoriamente la paridad y la alternancia (artículo 163 del Código de la Democracia). La candidatura a alcaldías elige una sola autoridad, lo que la coloca por fuera de la norma de paridad. 
Esta heterogeneidad arroja resultados distintos. Por un lado, el primado de hombres en el encabezado de las candidaturas a prefecto, segregó a las mujeres al bajísimo porcentaje de 13,8\% de candidatas mientras, en espejo, el porcentaje de candidatas a viceprefectas ascendió al $86,2 \%$, constituyendo de lejos el mayor porcentaje de candidaturas femeninas a cargos locales de las elecciones de febrero de 2014. En el caso de las alcaldías, la ventaja de la desventaja registrada en las candidaturas a viceprefectas, no se produce, colocándola como la más desigual de las dignidades que se eligen por votación directa a nivel local.

Estos resultados ponen un llamado de atención sobre la necesidad de discutir una reforma que haga posible una homogenización virtuosa de las candidaturas uninominales, las cuales deberían tomar la forma de candidaturas en binomio --tanto a nivel local como nacional-- para garantizar la aplicación de la normativa de igualdad y, al mismo tiempo, promover la modificación del tradicional encabezado masculino en busca de alcanzar mayor participación de mujeres en estos cargos donde el monopolio masculino de la representación se modifica muy lentamente.

\section{Candidatas a concejalas y a vocales de Juntas Parroquiales Rurales}

Debido a que las normas de paridad sí se aplican a las listas pluripersonales, los porcentajes de candidatización son más equitativos en las dignidades de los concejos municipales y en las juntas parroquiales rurales. Las candidatas a concejalas urbanas ascendieron a $45,4 \%$ y a $42,8 \%$ las candidatas a concejalas rurales. Las candidaturas femeninas a vocales de juntas parroquiales rurales se situaron en 43,1\%, el tercer lugar más alto entre todas las postulaciones locales. La siguiente tabla muestra los porcentajes de candidatas para todas las dignidades locales, ordenadas de mayor a menor: 
Tabla 2.

Candidatos/as por dignidad y sexo en orden según porcentajes

\begin{tabular}{c|c|c|c|c|c}
\hline \multirow{2}{*}{ Orden } & \multirow{2}{*}{ Dignidades } & \multicolumn{4}{|c}{ Candidatos } \\
\cline { 3 - 6 } & & Mujeres & $\%$ & Hombres & $\%$ \\
\hline $1^{\circ}$ & Vice-Prefecturas & 100 & 86,2 & 16 & 13,8 \\
\hline $2^{\circ}$ & Concejalías urbanas & 2608 & 45,4 & 3137 & 54,6 \\
\hline $3^{\circ}$ & Vocalías Juntas Parroquiales Rurales & 8037 & 43,1 & 10616 & 56,9 \\
\hline $4^{\circ}$ & Concejalías rurales & 1055 & 42,8 & 1410 & 57,2 \\
\hline $5^{\circ}$ & Prefecturas & 16 & 13,8 & 100 & 86,2 \\
\hline $6^{\circ}$ & Alcaldías & 147 & 12,2 & 1054 & 87,8 \\
\hline
\end{tabular}

Fuente: CNE, Elecciones 2014

Elaboración: María Arboleda

\section{Principales y suplentes: subalternización de género} en las candidaturas pluripersonales

Más allá de las normas de paridad y alternancia, la subalternización de las mujeres en el proceso electoral se expresa como una relación desbalanceada entre candidatas principales y suplentes. El documento Indicadores de Participación Política de la Mujer Ecuatoriana (CNE, 2014a), muestra a las mujeres subrepresentadas en las candidaturas principales $(42,1 \%)$, mientras del total de personas que ocuparon candidaturas suplentes, la mayoría $(56,5 \%)$ fueron mujeres. 
Gráfico 3.

Candidaturas principales versus suplentes por sexo

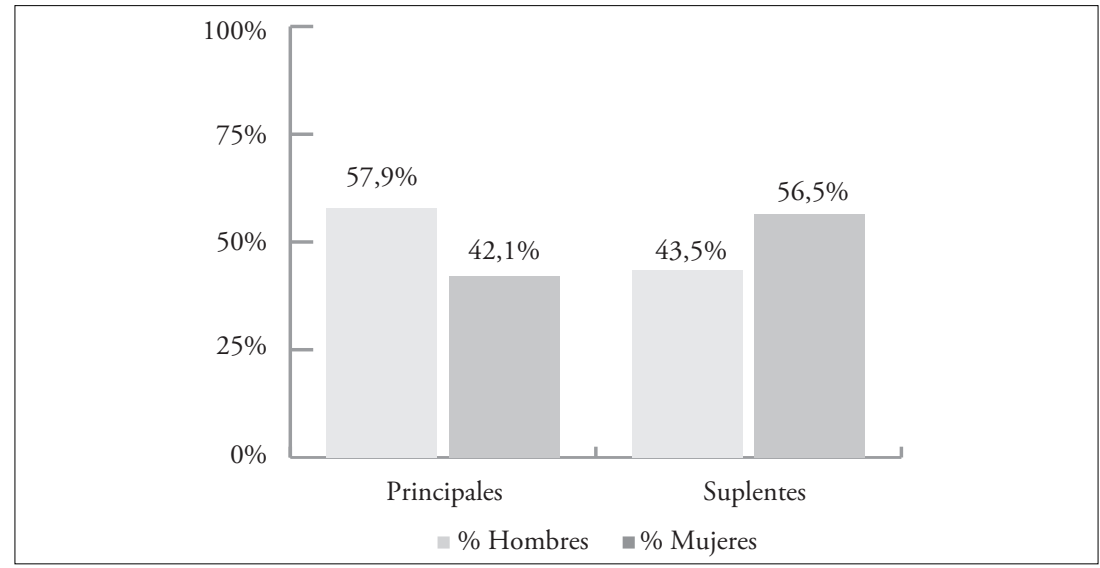

Fuente: CNE, Elecciones 2014

Elaboración: P. Jaramillo

Esta disimetría en espejo es también un efecto de la práctica de integración de las listas principales con primacía del encabezado masculino. Por lo demás esta práctica -al aplicarse a las dignidades en las que se eligen cargos en número impar--, contribuye al no logro cuantitativo de la paridad, como hemos seńalado en acápite de análisis del sistema electoral ecuatoriano. Vale resaltar que en calidad de suplentes, las mujeres fueron mayoría en todos las candidaturas a cargos plurinominales: el $57,2 \%$ como candidatas a concejalas rurales suplentes, el 56,8\% a vocales suplentes de juntas parroquiales rurales y el 54,6\% a concejalas urbanas suplentes. Señalamos por otro lado que, aunque el cargo de viceprefectas no constituye en derecho una suplencia puesto que posee un rango de autoridad par, la simbolización normativa y social de esta dignidad le otorga un lugar menor. Allí, como hemos señalado, las mujeres fueron la más grande mayoría como candidatas con un 86,2\%. 


\section{Las ecuatorianas como autoridades electas}

\section{Solo una cuarta parte de mujeres entre los electos}

En relación con la paridad, la mayor distancia generada en las elecciones de febrero de 2014, proviene de la participación de mujeres en apenas un cuarto del total de electos. Por causa de esta brecha, el CNE declaró críticamente: "la relación entre hombres y mujeres (electos/a) es de 3 a 1; es decir por cada mujer que fue electa en las elecciones seccionales de 2014, fueron electos 3 hombres" (CNE, 2014: 33). Estos resultados corresponden a 1448 mujeres electas $(25,7 \%)$ frente a 4184 hombres electos $(74,3 \%)$.

\section{Gráfico 4.}

Autoridades locales electoras por sexo

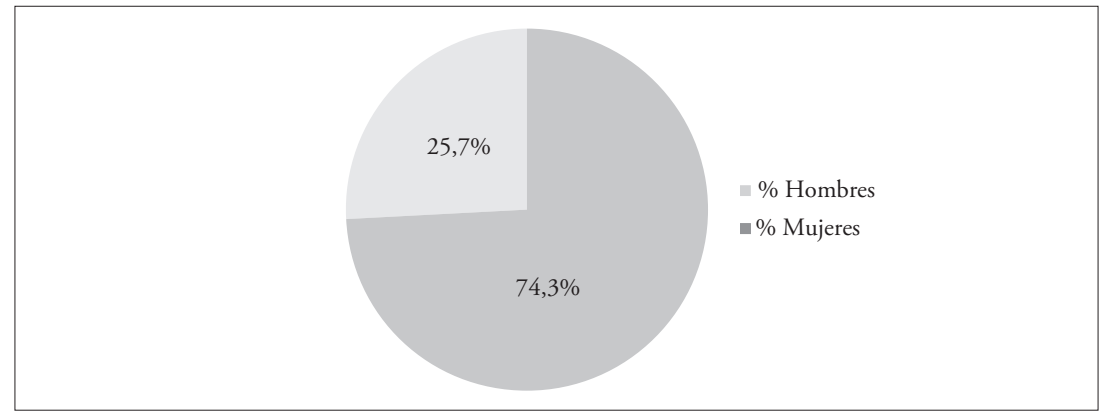

Fuente: CNE, Elecciones 2014

Elaboración: P. Jaramillo

En el elenco de dignidades electas, algunos cargos muestran peor desempeño que otros. Los resultados más bajos se obtuvieron en alcaldías con un 7,2\% de alcaldesas y con el 8,7 \% de prefectas electas. En las otras dignidades, se eligió un 33,9\% de concejalas urbanas, un 24,9\% de concejalas rurales y un $25,1 \%$ de mujeres vocales de juntas parroquiales rurales. Al mismo tiempo, el mejor desempeño en todas las dignidades electas fue el notable 91,3\% de mujeres viceprefectas (21 de 23), que ocurre gracias a la aplicación de la norma de paridad pero, 
como hemos dicho, debido al dominio masculino en el encabezado de listas para prefectos.

Estos datos ratifican también el orden constelado del campo electoral, donde algunas dignidades son astros mayores como las alcaldías, algunas de ellas muy disputadas por el rango práctico y simbólico que poseen como antesalas de mayores avances en una carrera política ${ }^{9}$. Los resultados generales se muestran en el siguiente gráfico.

\section{Gráfico 5 .}

Autoridades locales electas por dignidad y sexo

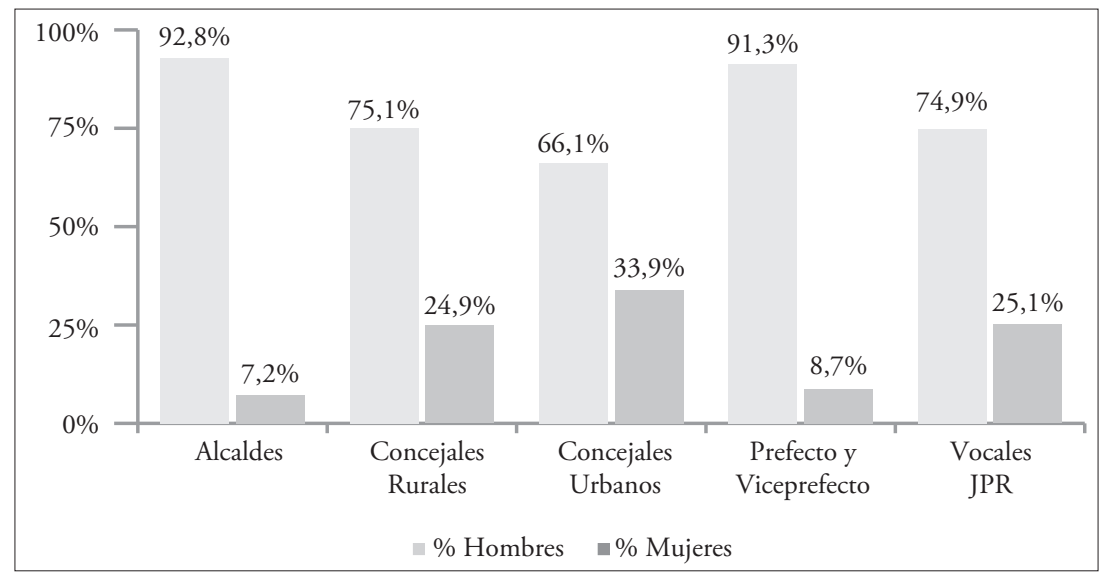

Fuente: CNE, Elecciones 2014

Elaboración: P. Jaramillo

En la distribución de electas en todas las dignidades con porcentajes superiores al promedio nacional (25,7\%), destacan 12 provincias: Los Ríos, Guayas, Santa Elena, Santo Domingo Tsáchilas, El Oro, Imbabura, Manabí, Pichincha, Esmeraldas, Cañar, Sucumbíos y Azuay, en ese orden. Napo registró un comportamiento similar a la tendencia nacional con $25,6 \%$ de electas. En cambio, 10 provincias eligieron a mujeres

9 El dominio masculino en las alcaldías, que en ciudades capitales de país o de gran peso económico y/o poblacional se considera un escalón a la Presidencia de la República, mientras muchas mujeres se convertían en concejalas dio pie, en los años 90s, a la tesis de la entrada de las mujeres al poder municipal por la puerta pequeña. 
en porcentajes inferiores (entre 24,9\% y 18,1\%): Carchi, Chimborazo, Pastaza, Loja, Galápagos, Zamora Chinchipe, Orellana, Tungurahua, Morona Santiago y, en último lugar, Cotopaxi. Solo Esmeraldas y Orellana eligieron prefectas, ambas re-electas, mientras las restantes 21 provincias, con excepción de Galápagos que no elige autoridades provinciales, cuentan con viceprefectas.

\section{Gráfico 6.}

Mujeres autoridades electas por provincia

(todas las dignidades)

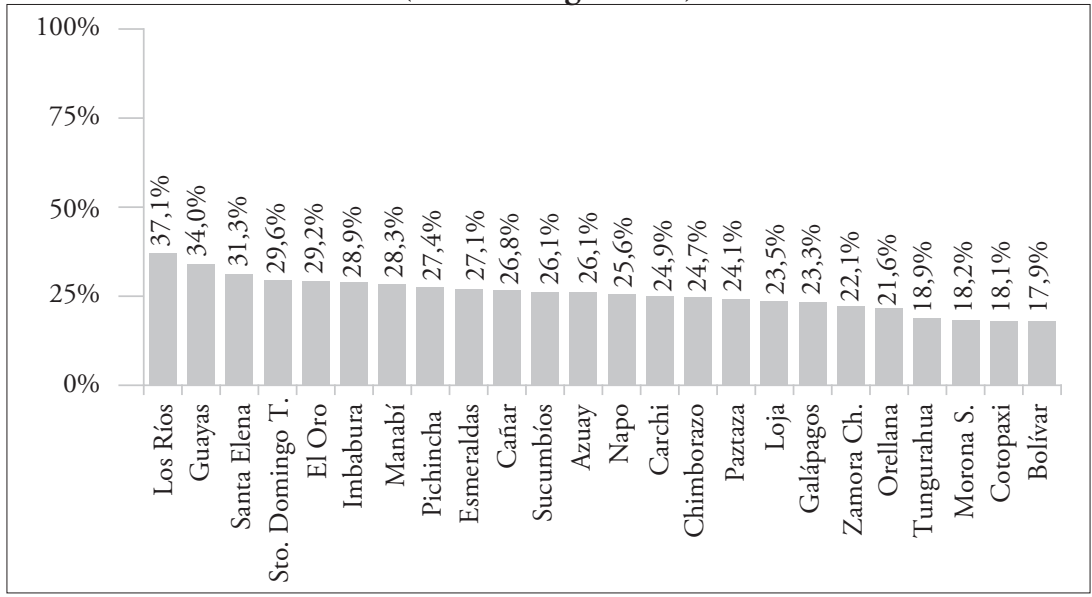

Fuente: CNE, Elecciones 2014

Elaboración: P. Jaramillo

A nivel municipal, tan solo 16 cantones eligieron alcaldesas de un total de 221 y se concentran en nueve provincias: Guayas (Durán, Isidro Ayora, Milagro, Nobol y Playas); Azuay (Nabón y Oña); Loja (Catamayo y Zapotillo); Pichincha (Puerto Quito y San Miguel de los Bancos); El Oro (Portovelo), Los Ríos (Baba), Manabí (San Vicente), Orellana (Francisco de Orellana) y Sucumbíos (Putumayo). La alcaldesa de Francisco de Orellana es la única en ocupar esta dignidad en una capital de provincia. Pichincha y Orellana, porcentualmente, son las provincias con la más alta participación femenina en este cargo local, con 25\% 
de alcaldesas cada una. Le sigue Guayas, la provincia con mayor número de alcaldesas (5), con el 20\% del total provincial. En Sucumbíos, el porcentaje de alcaldesas electas ascendió a 14,3\% , en Azuay a 13,3\%, en Loja al 12,5\%, en Los Ríos al 7,7\%, en El Oro al 7,1\%, en Manabí al 4,54\%. En Guayas y Azuay algunos municipios vienen re-eligiendo alcaldesas por varios períodos.

Tabla 3.

Alcaldesas electas según provincia, número y porcentaje

\begin{tabular}{c|c|c|c}
\hline \multirow{2}{*}{ Provincia } & \multirow{2}{*}{ No. } & \multirow{2}{*}{ \% provincial } & Alcaldesas / Municipios \\
\hline Pichincha & 2 & \multirow{2}{*}{25} & Puerto Quito \\
\hline Orellana & 1 & 25 & San Miguel de los Bancos \\
\hline \multirow{2}{*}{ Guayas } & \multirow{2}{*}{5} & \multirow{2}{*}{20} & Francisco de Orellana \\
\cline { 4 - 4 } & & & Durán \\
\cline { 4 - 4 } & & & Isidro Ayora \\
\cline { 4 - 4 } & & & Milagro \\
\hline Sucumbíos & 1 & 14,3 & Playas \\
\hline Azuay & 2 & 13,3 & Putumayo \\
\hline Loja & 2 & 12,5 & Nabón \\
\hline Los Ríos & 1 & 7,7 & Catamayo \\
\hline El Oro & 1 & 7,1 & Zapotillo \\
\hline Manabí & 1 & 4,5 & Baba \\
\hline
\end{tabular}

Fuente: CNE, 2014; CNE, 2014a

Elaboración: María Arboleda

Del total de 867 concejales urbanos electos, solo 294 (33,9\%) fueron mujeres. Las provincias, ordenadas de mayor a menor, según porcentajes de concejalas urbanas electas, constan en la siguiente tabla. 
Tabla 4.

Concejalas urbanas electas según porcentaje provincial

\begin{tabular}{|c|c|c|}
\hline Orden & Provincia & Porcentaje \\
\hline 1 & Santo Domingo de los Tsáchilas & $60,0 \%$ \\
\hline 2 & Los Ríos & $45,8 \%$ \\
\hline 3 & Sucumbíos & $42,1 \%$ \\
\hline 4 & Imbabura & $40,9 \%$ \\
\hline 5 & Guayas & $39,4 \%$ \\
\hline 6 & El Oro & $38,3 \%$ \\
\hline 7 & Cotopaxi & $36,4 \%$ \\
\hline 8 & Cañar & $35,7 \%$ \\
\hline 9 & Santa Elena & $35,7 \%$ \\
\hline 10 & Manabí & $35,0 \%$ \\
\hline 11 & Bolívar & $33,3 \%$ \\
\hline 12 & Azuay & $32,1 \%$ \\
\hline 13 & Zamora Chinchipe & $30,8 \%$ \\
\hline 14 & Tungurahua & $30,6 \%$ \\
\hline 15 & Pichincha & $30,2 \%$ \\
\hline 16 & Orellana & $30,0 \%$ \\
\hline 17 & Morona Santiago & $25,8 \%$ \\
\hline 18 & Chimborazo & $25,0 \%$ \\
\hline 19 & Loja & $24,5 \%$ \\
\hline 20 & Esmeraldas & $22,7 \%$ \\
\hline 21 & Carchi & $22,2 \%$ \\
\hline 22 & Napo & $18,8 \%$ \\
\hline 23 & Pastaza & $16,7 \%$ \\
\hline 24 & Galápagos & $16,7 \%$ \\
\hline
\end{tabular}

Fuente: CNE, 2014

Elaboración: María Arboleda

En 14 capitales provinciales y en Santa Cruz (Galápagos) ${ }^{10}$, las concejalas urbanas electas obtuvieron porcentajes mayores que el promedio de su provincia. Por el contrario, en cuatro capitales, los porcentajes de concejalas urbanas son menores al promedio provincial. En cinco de

10 Para el caso de Galápagos se decidió incluir a Santa Cruz en lugar de Puerto Baquerizo Moreno, la capital regional, por su peso poblacional. 
estas ciudades, no se eligió ninguna concejala urbana: Zamora, Pastaza, Tena, Morona y Riobamba. Ver Tabla 5.

Tabla 5 .

Concejales urbanas en provincias y en sus capitales

(ordenadas según porcentaje)

\begin{tabular}{c|c|c|c|c}
\hline No. & Provincia & $\%$ & Capital & $\%$ \\
\hline \multicolumn{2}{c|}{ Capitales con Porcentaje de Concejalas Urbanas Superior al Promedio Provincial } \\
\hline 1 & Santo Domingo de los Tsáchilas & $60,0 \%$ & Santo Domingo & $72,7 \%$ \\
\hline 2 & Cotopaxi & $36,4 \%$ & Latacunga & $60,0 \%$ \\
\hline 3 & Imbabura & $40,9 \%$ & Ibarra & $57,1 \%$ \\
\hline 4 & Tungurahua & $30,6 \%$ & Ambato & $57,1 \%$ \\
\hline 5 & Guayas & $39,4 \%$ & Guayaquil & $50,0 \%$ \\
\hline 6 & Bolívar & $33,3 \%$ & Guaranda & $50,0 \%$ \\
\hline 7 & Azuay & $32,1 \%$ & Cuenca & $50,0 \%$ \\
\hline 8 & Sucumbíos & $42,1 \%$ & Lago Agrio & $50,0 \%$ \\
\hline 9 & Orellana & $30,0 \%$ & Fco. de Orellana & $50,0 \%$ \\
\hline 10 & Los Ríos & $45,8 \%$ & Babahoyo & $50,0 \%$ \\
\hline 11 & Pichincha & $30,2 \%$ & Quito & $46,7 \%$ \\
\hline 12 & El Oro & $38,3 \%$ & Machala & $40,0 \%$ \\
\hline 13 & Loja & $24,5 \%$ & Loja & $33,3 \%$ \\
\hline 14 & Galápagos & $22,7 \%$ & Esmeraldas & $25,0 \%$ \\
\hline 15 & Esmeraldas & Santa Cruz & $25,0 \%$ \\
\hline
\end{tabular}

Capitales con porcentaje de concejalas urbanas inferior al provincial o sin mujeres electas en esta dignidad

\begin{tabular}{c|c|c|c|c}
\hline 16 & Santa Elena & $35,7 \%$ & Santa Elena & $33,3 \%$ \\
\hline 17 & Manabí & $35,0 \%$ & Portoviejo & $33,3 \%$ \\
\hline 18 & Cañar & $35,7 \%$ & Azogues & $25,0 \%$ \\
\hline 19 & Carchi & $22,2 \%$ & Tulcán & $20,0 \%$ \\
\hline 20 & Zamora Chinchipe & $30,8 \%$ & Zamora & $0,0 \%$ \\
\hline 21 & Morona Santiago & $25,8 \%$ & Macas & $0,0 \%$ \\
\hline 22 & Napo & $18,8 \%$ & Tena & $0,0 \%$ \\
\hline 23 & Chimborazo & $25,0 \%$ & Riobamba & $0,0 \%$ \\
\hline 24 & Pastaza & $16,7 \%$ & Puyo & $0,0 \%$ \\
\hline
\end{tabular}

Fuente: CNE, Elecciones 2014

Elaboración: María Arboleda

11 Recuérdese que para el caso de Galápagos se incluye a Santa Cruz en lugar de Puerto Baquerizo Moreno, la capital regional, por su peso poblacional. 


\section{Gráfico 7.}

Concejales/as urbanos/as electas en las capitales de provincia

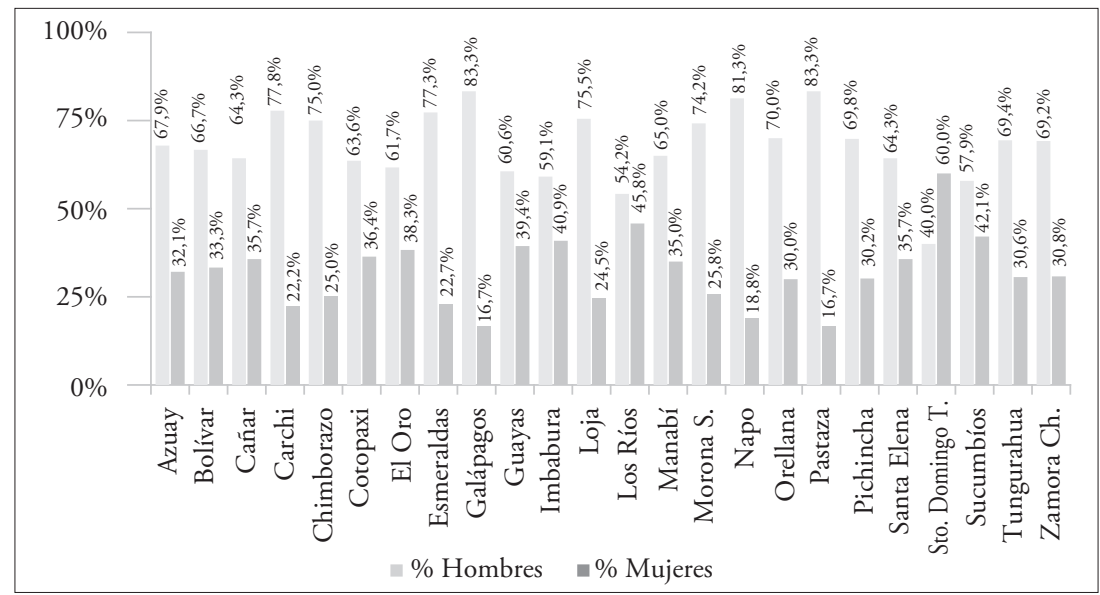

Fuente: CNE, Elecciones 2014

Elaboración: P. Jaramillo

Las concejalas rurales, por su parte, alcanzaron un 24,9\% de electas (109), frente al 75,1\% de hombres (329). Es el más bajo porcentaje entre todos los cargos locales pluripersonales. La provincia de Santa Elena alcanzó la mayor tasa de concejalas rurales con 44,4\%, mientras en 13 provincias ellas obtuvieron porcentajes por encima del promedio nacional de 24,9\%. En la región especial de Galápagos no se eligió a ninguna mujer para esta dignidad. 10 provincias alcanzaron porcentajes de concejalas rurales por debajo del promedio, (entre 21,1\% y 10\%). Ver Tabla 6. 
Tabla 6.

Concejalas rurales electos/as por sexo y provincias

(ordenadas según porcentaje)

\begin{tabular}{|c|c|c|}
\hline No. & Provincia & $\%$ Mujeres \\
\hline \multicolumn{3}{|c|}{ Porcentaje de concejalas electas por encima del promedio nacional $(24,9 \%)$} \\
\hline 1 & Santa Elena & $44,4 \%$ \\
\hline 2 & Cañar & $38,5 \%$ \\
\hline 3 & Napo & $36,4 \%$ \\
\hline 4 & Carchi & $35,7 \%$ \\
\hline 5 & Santo Domingo de los Tsáchilas & $33,3 \%$ \\
\hline 6 & Loja & $32,4 \%$ \\
\hline 7 & El Oro & $31,8 \%$ \\
\hline 8 & Tungurahua & $31,6 \%$ \\
\hline 9 & Imbabura & $31,3 \%$ \\
\hline 10 & Manabí & $30,6 \%$ \\
\hline 11 & Pastaza & $30,0 \%$ \\
\hline 12 & Azuay & $28,1 \%$ \\
\hline 13 & Los Ríos & $25,0 \%$ \\
\hline \multicolumn{3}{|c|}{ Porcentaje de concejalas electas por debajo del promedio nacional $(24,9 \%)$} \\
\hline 14 & Zamora Chinchipe & $21,1 \%$ \\
\hline 15 & Pichincha & $21,1 \%$ \\
\hline 16 & Esmeraldas & $19,0 \%$ \\
\hline 17 & Guayas & $16,7 \%$ \\
\hline 18 & Sucumbíos & $16,7 \%$ \\
\hline 19 & Orellana & $16,7 \%$ \\
\hline 20 & Chimborazo & $15,0 \%$ \\
\hline 21 & Cotopaxi & $14,3 \%$ \\
\hline 22 & Morona Santiago & $13,8 \%$ \\
\hline 23 & Bolívar & $10,0 \%$ \\
\hline 24 & Galápagos & $0,0 \%$ \\
\hline
\end{tabular}

Fuente: CNE, Elecciones 2014

Elaboración: María Arboleda 
Gráfico 8.

Concejales/as rurales electos/as por sexo y provincia

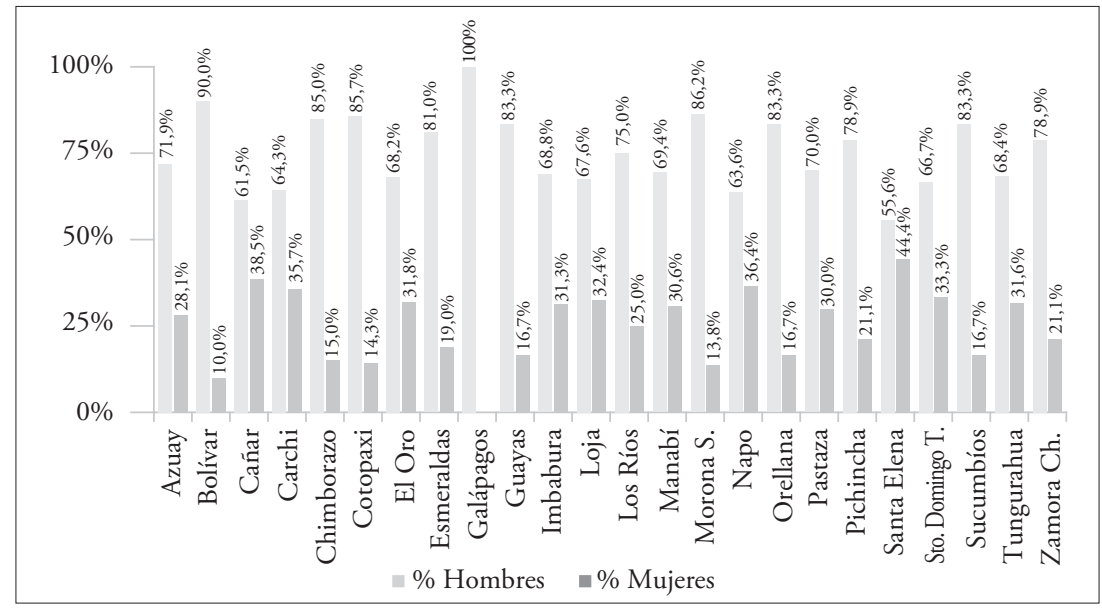

Fuente: CNE, Elecciones 2014

Elaboración: P. Jaramillo

Las diferencias entre las concejalas rurales electas en capitales de provincia respecto del promedio provincial son destacables: la ciudad de Tena obtuvo el más alto porcentaje de concejalas rurales: 66,7\%. Le siguen Cuenca (60\%), Zamora, Ibarra, Santo Domingo y Loja con 50\% cada una, y 8 ciudades con 33,3\% de concejalas rurales: Ambato, Azogues, Babahoyo, Lago Agrio, Puyo, Quito, Riobamba y Santa Elena. Sin embargo, 11 capitales no eligieron a ninguna mujer en estos cargos: Esmeraldas, Francisco de Orellana, Guaranda, Guayaquil, Latacunga, Machala, Morona, Portoviejo, Santa Cruz y Tulcán. 


\section{Gráfico 9.}

Concejales/as rurales electos/as en las capitales de provincia

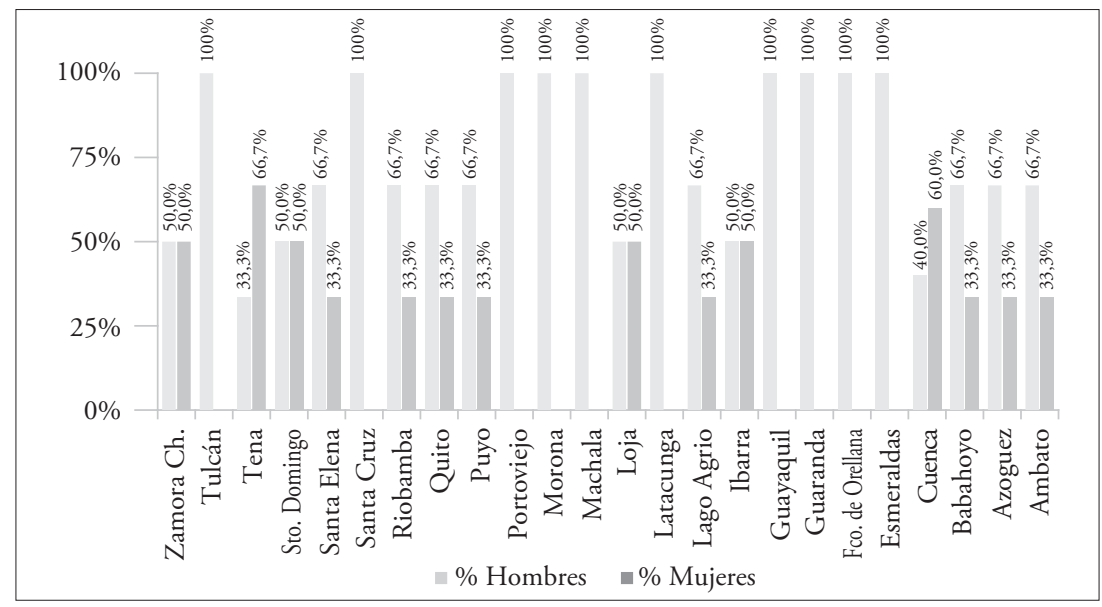

Fuente: CNE, Elecciones 2014

Elaboración: P. Jaramillo

Las mujeres electas como vocales de juntas parroquiales rurales registraron el 25,1\%. Las diferencias entre provincias oscilan entre 38,8\% en Los Ríos y 15,8\% en Bolívar. En 15 provincias las vocales obtuvieron porcentajes mayores al promedio nacional (entre 38,8\% y 25,4\%): Los Ríos, Guayas, Galápagos, Santa Elena, Esmeraldas, Imbabura, El Oro, Pichincha, Napo, Chimborazo, Sucumbíos, Pastaza, Azuay, Cañar y Carchi, en este orden. 
Gráfico 10.

Vocales de Juntas Parroquiales Rurales electos/as por sexo y provincia

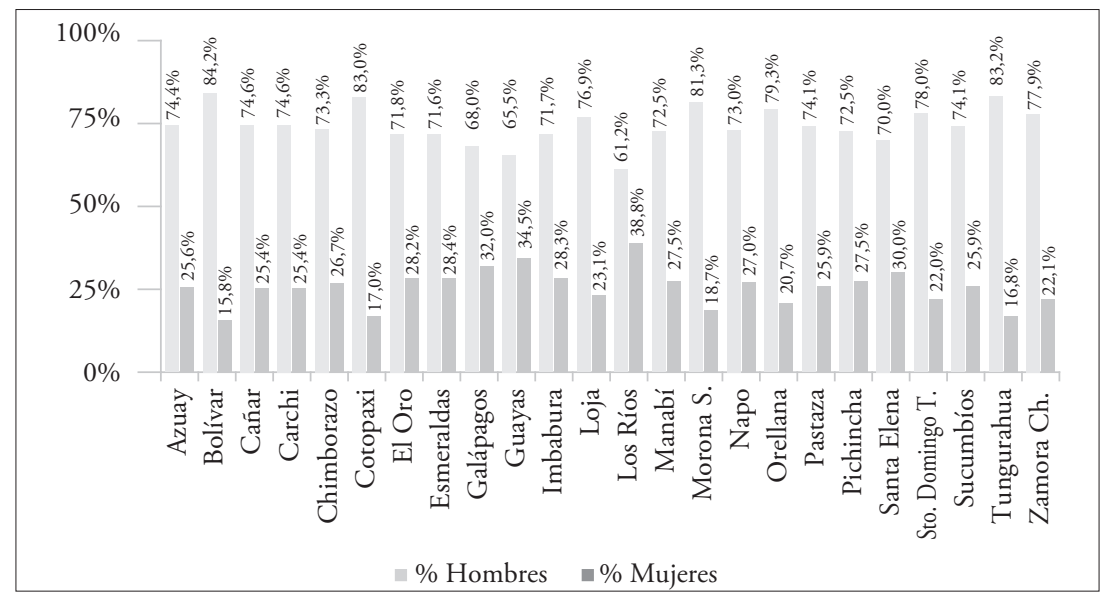

Fuente: CNE, Elecciones 2014

Elaboración: P. Jaramillo

\section{Mujeres jóvenes emergiendo a la política}

Las candidaturas femeninas registradas en 2014 revelan un fenómeno singular: un alto porcentaje de mujeres jóvenes menores de 30 años fueron candidatizadas alcanzando en un rango de $66,8 \%$. Los rendimientos, sin embargo, como se aprecia, pasan factura a las jóvenes, puesto que aunque el porcentaje de electas en este rango de edad se mantiene como el mayor entre las mujeres, baja a 51,1\% comparado con el de los hombres electos en la misma edad, que suben a 48,5\% desde un 33,2\% de candidaturas en este mismo rango etáreo. Nótese sin embargo, que el porcentaje de mujeres electas menores de 30 ańos, alcanza la paridad, hecho que representa, quizá, el cambio más notable en la construcción social de la participación de las ecuatorianas en la política. 
Tabla 7.

Candidatos/as y electos/as por grupo etario

\begin{tabular}{c|c|c|c|c}
\hline \multirow{2}{*}{ Rango de edad } & \multicolumn{2}{|c|}{ Candidaturas } & \multicolumn{2}{c}{ Electas } \\
\cline { 2 - 5 } & Mujeres & Hombres & Mujeres & Hombres \\
\cline { 2 - 5 } & $\%$ & $\%$ & $\%$ & $\%$ \\
\hline Menores de 30 & 66,8 & 33,2 & 51,5 & 48,5 \\
\hline $30-45$ & 43,1 & 56,9 & 25,9 & 74,1 \\
\hline $45-65$ & 27,2 & 72,8 & 16,2 & 83,8 \\
\hline 65 y más & 14,7 & 85,3 & 11,5 & 88,5 \\
\hline Total & 37,95 & $\mathbf{6 2 , 0 5}$ & $\mathbf{2 6 , 3}$ & 73,7 \\
\hline
\end{tabular}

Fuente: CNE, Elecciones 2014

Elaboración: María Arboleda

La presencia en la política de mujeres en la plenitud de su etapa reproductiva como muestran los resultados de 2014, coloca en primer plano el tema de la conciliación de las esferas doméstica y pública así como la necesidad de avanzar en la responsabilidad masculina y estatal sobre los cuidados. Es destacable también que, mientras los porcentuales de candidatas y electas disminuye progresivamente en los 3 rangos de mayor edad, para los hombres sucede exactamente al revés, su participación se incrementa conforme aumentan en edad.

A nivel de las provincias, 9 registraron los más altos porcentajes de electoras menores de 18 años: Santa Elena, Cañar, Chimborazo, Sucumbíos, Imbabura, Loja, Santo Domingo de los Tsáchilas, Los Ríos y Zamora Chinchipe. Mientras, doce capitales de provincia se destacaron en el mismo sentido: Azogues, Santa Elena, Loja, Lago Agrio, Guaranda, Riobamba, Ibarra. Morona, Santo Domingo, Francisco de Orellana, Esmeraldas y Babahoyo. Ver tabla. 
Tabla 8.

Electores entre 16 y 18 ańos por sexo, provincia y capital provincial

\begin{tabular}{|c|c|c|c|c|c|}
\hline Provincia & Hombres & Mujeres & Capital & Hombres & Mujeres \\
\hline Azuay & $51,05 \%$ & $48,95 \%$ & Cuenca & $51,0 \%$ & $49,0 \%$ \\
\hline Bolívar & $50,82 \%$ & $49,18 \%$ & Guaranda & $49,7 \%$ & $50,3 \%$ \\
\hline Cañar & $49,93 \%$ & $50,07 \%$ & Azogues & $49,5 \%$ & $50,5 \%$ \\
\hline Carchi & $50,53 \%$ & $49,47 \%$ & Tulcán & $50,9 \%$ & $49,1 \%$ \\
\hline Cotopaxi & $50,85 \%$ & $49,15 \%$ & Latacunga & $50,9 \%$ & $49,1 \%$ \\
\hline Chimborazo & $50,03 \%$ & $49,97 \%$ & Riobamba & $49,9 \%$ & $50,1 \%$ \\
\hline El Oro & $51,03 \%$ & $48,97 \%$ & Machala & $51,2 \%$ & $48,8 \%$ \\
\hline Esmeraldas & $51,19 \%$ & $48,81 \%$ & Esmeraldas & $50,6 \%$ & $49,4 \%$ \\
\hline Guayas & $51,01 \%$ & $48,99 \%$ & Guayaquil & $51,0 \%$ & $49,0 \%$ \\
\hline Imbabura & $50,17 \%$ & $49,83 \%$ & Ibarra & $49,9 \%$ & $50,1 \%$ \\
\hline Loja & $50,23 \%$ & $49,77 \%$ & Loja & $49,7 \%$ & $50,3 \%$ \\
\hline Los Ríos & $50,28 \%$ & $49,72 \%$ & Babahoyo & $50,6 \%$ & $49,4 \%$ \\
\hline Manabí & $51,09 \%$ & $48,91 \%$ & Portoviejo & $50,9 \%$ & $49,1 \%$ \\
\hline Morona Santiago & $51,17 \%$ & $48,83 \%$ & Macas & $50,5 \%$ & $49,5 \%$ \\
\hline Napo & $51,19 \%$ & $48,81 \%$ & Tena & $52,0 \%$ & $48,0 \%$ \\
\hline Pastaza & $50,59 \%$ & $49,41 \%$ & Puyo & $50,9 \%$ & $49,1 \%$ \\
\hline Pichincha & $50,99 \%$ & $49,01 \%$ & Quito & $51,0 \%$ & $49,0 \%$ \\
\hline Tungurahua & $50,65 \%$ & $49,35 \%$ & Ambato & $51,1 \%$ & $48,9 \%$ \\
\hline Zamora Chinchipe & $50,38 \%$ & $49,62 \%$ & Zamora & $52,3 \%$ & $47,7 \%$ \\
\hline Galápagos & $51,24 \%$ & $48,76 \%$ & Santa Cruz & $52,6 \%$ & $47,4 \%$ \\
\hline Sucumbíos & $50,14 \%$ & $49,86 \%$ & Lago Agrio & $49,7 \%$ & $50,3 \%$ \\
\hline Orellana & $51,21 \%$ & $48,79 \%$ & Fco. de Orellana & $50,6 \%$ & $49,4 \%$ \\
\hline $\begin{array}{c}\text { Santo Domingo de } \\
\text { los Tsáchilas }\end{array}$ & $50,27 \%$ & $49,73 \%$ & Santo Domingo & $50,6 \%$ & $49,4 \%$ \\
\hline Santa Elena & $48,77 \%$ & $51,23 \%$ & Santa Elena & $49,6 \%$ & $50,4 \%$ \\
\hline
\end{tabular}

Fuente: CNE, 2014

Elaboración: María Arboleda 


\section{Resultados para las mujeres según tamaño de las circunscripciones}

Una revisión de las mujeres electas como concejalas urbanas y rurales según el tamaño de las circunscripciones (medianas, pequeñas y únicas, pares e impares), en las cuales se aplican las normas de paridad y alternancia, arroja resultados diferenciados que vale la pena analizar.

\section{Gráfico 11.}

Concejales urbanos: candidatos y electos por sexo y tamańo de circunscripción

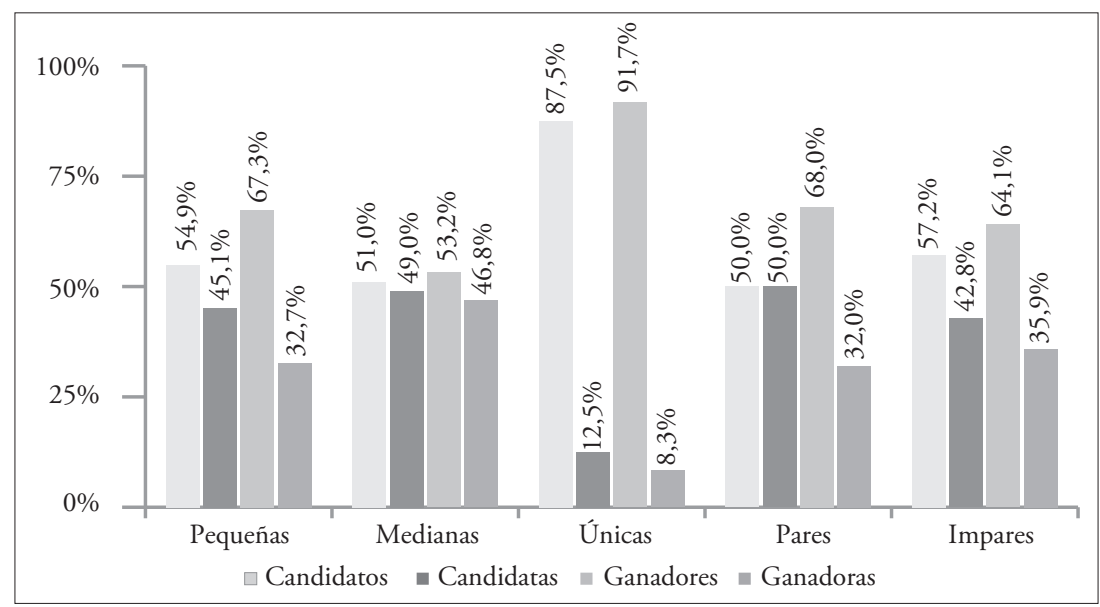

Fuente: CNE, Elecciones 2014

Elaboración: P. Jaramillo

En efecto, si se analizan el gráfico inserto arriba, se aprecia que en el caso de las concejalías urbanas, en las circunscripciones medianas y pares, la candidatización muestra igualdad de oportunidades, es decir se cumplen tasas iguales o cercanas a la paridad. De modo similar, la brecha entre mujeres y hombres en los resultados es sensiblemente menor con $53,2 \%$ para ellos y $46,8 \%$ para ellas. Es decir, una diferencia de apenas $6,4 \%$.

No ocurre lo mismo en las circunscripciones pequeñas y en las impares: en ambas la brecha de candidatización oscila en torno a los diez 
puntos mientras los candidatos hombres consiguen ser electos en más del $50 \%$ que las mujeres en las pequeñas circunscripciones $(67,3 \%$ para ellos y $32,7 \%$ para ellas). En ambos casos, los resultados favorecen a los hombres. Así mismo, en las circunscripciones únicas, las brechas de género tanto en la candidatización como en la elección es aún más marcada $(87,5 \%$ de hombres candidatos vs. $12 \%$ de mujeres candidatas; $91,7 \%$ de hombres electos vs. $8,7 \%$ de mujeres electas).

\section{Gráfico 12 .}

Concejales rurales: candidatos y electos por sexo y tamaño de circunscripción

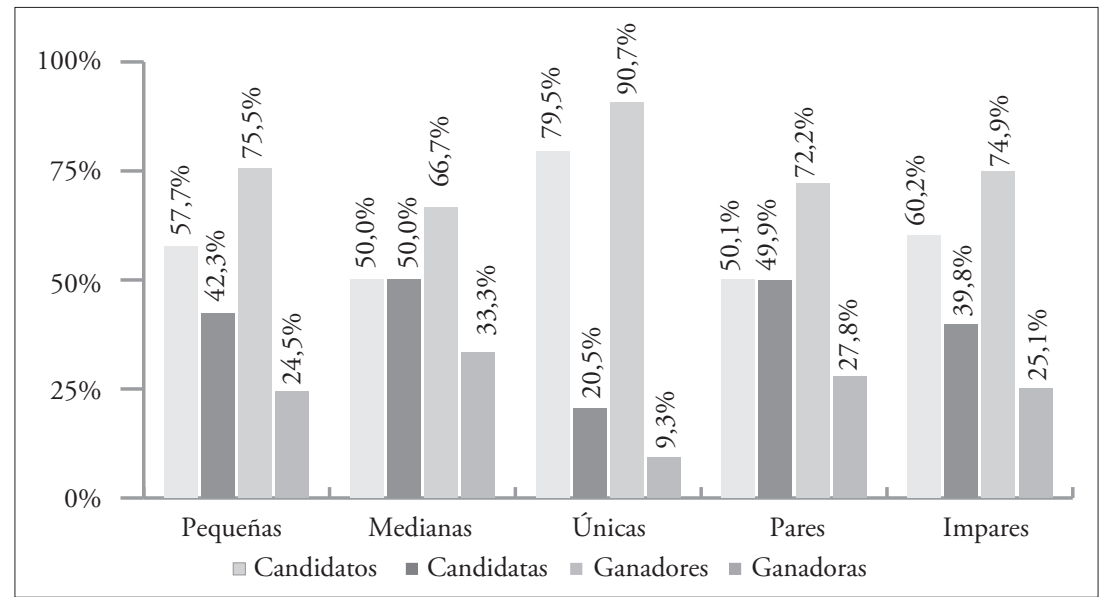

Fuente: CNE, Elecciones 2014

Elaboración: P. Jaramillo

Por el contrario, en el caso de las concejalías rurales, como se aprecia en el cuadro inserto arriba, aunque mujeres y hombres registran paridad en la candidatización en las circunscripciones medianas y en las pares, las brechas en los resultados son mayores que a nivel urbano, sobre todo en las circunscripciones pares, donde los hombres (72,2\%) superan a las mujeres electas $(27,8 \%)$ con 41 puntos de diferencia. Por su parte, 
en las circunscripciones pequeñas e impares del ámbito rural municipal, la situación es en todo negativa para las mujeres: tanto la candidatización muestra brechas mayores que las del promedio nacional y que las registradas a nivel de las circunscripciones urbanas, y los resultados favorecen a los hombres al menos con 50 puntos de diferencia.

En las circunscripciones únicas para concejalías a nivel rural, se registra un porcentaje de candidaturas femeninas más alto $(20,5 \%)$ que las inscritas a nivel urbano (12,5\%), mientras los hombres electos obtienen una representación mayor en más de 80 puntos que ellas, es decir una brecha en exceso sensible.

Estas evidencias abonan la idea de la necesidad de encontrar una nueva geometría electoral que favorezca el establecimiento de circunscripciones de mayor tamaño, como prometedoras de mayor equidad para las mujeres. En cambio, frente a las implicaciones negativas para ellas del número impar de cargos, emerge la propuesta de normar en ellas un obligatorio encabezamiento femenino, tal como ha sido aprobado en las últimas semanas en Bolivia (TSE Bolivia, 2014).

\section{Mujeres postergadas en el encabezado de listas}

Los datos de las elecciones seccionales de 2014 lo comprueban: el encabezado de listas pluripersonales a nivel urbano y rural y de listas pares como impares, es de control hegemónico masculino: un 74,9\% a nivel urbano y un $73,3 \%$ a nivel rural son los porcentajes de hombres que encabezan listas pares, mientras un $81,8 \%$ a nivel urbano y un $81,7 \%$ a nivel rural son los porcentajes de hombres que encabezan listas de concejalías impares. Como se aprecia, la distancia es mayor en 7 u 8 puntos en las listas impares frente a las listas pares. 
Gráfico 13.

Candidatos según encabezamiento de la lista por nominación par e impar por sexo y porcentaje

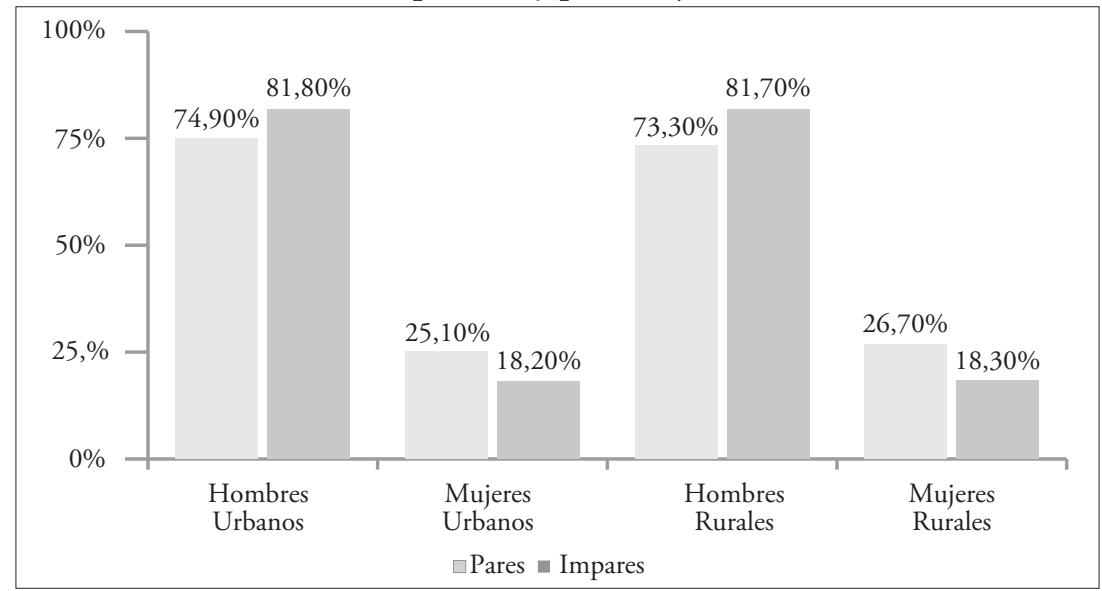

Fuente: CNE, Elecciones 2014

Elaboración: P. Jaramillo

\section{Comportamientos electorales y género: algunos indicios}

Una exploración sobre el comportamiento electoral de mujeres y hombres, en relación con 5 candidatas electas el pasado febrero (las dos únicas prefectas y una alcaldesa por Costa, Sierra y Oriente en los municipios de mayor población donde fueron elegidas), arroja indicios de posibles comportamientos diferenciados por género. Desde luego, estos indicios no constituyen evidencias conclusivas y advertimos además que la comparación se realiza solo sobre los datos electores, haciendo salvedad de factores que pueden incidir en los comportamientos electorales, sobre lo que no contamos con información. ${ }^{12}$

12 Cavenaghi y Alves (2012, 109-115) sostienen que factores como la clase social, el nivel de escolaridad, las creencias religiosas, la región de residencia, la vinculación a programas sociales, la edad, las características del/a candidato/a, el programa de gobierno, entre otros, actúan junto a la variable sexo y muchas veces tienen mayor peso que éste último en definir las intenciones de voto. 
En todo caso, si se comparan los gráficos insertos abajo se aprecia que tanto en el caso de las prefectas como de las alcaldesas, en la Amazonía más hombres votaron por una mujer, mientras en la Costa más mujeres votaron por una mujer, aunque en porcentajes que no llegan a los 6 puntos. En la región Sierra no existen prefectas electas y no es posible comparar, sin embargo, nótese que en Catamayo (Loja), un mayor porcentaje de mujeres votó por una mujer.

\section{Gráfico 14.}

Sufragantes según sexo que votaron por las candidatas a prefectas en Esmeraldas y Orellana

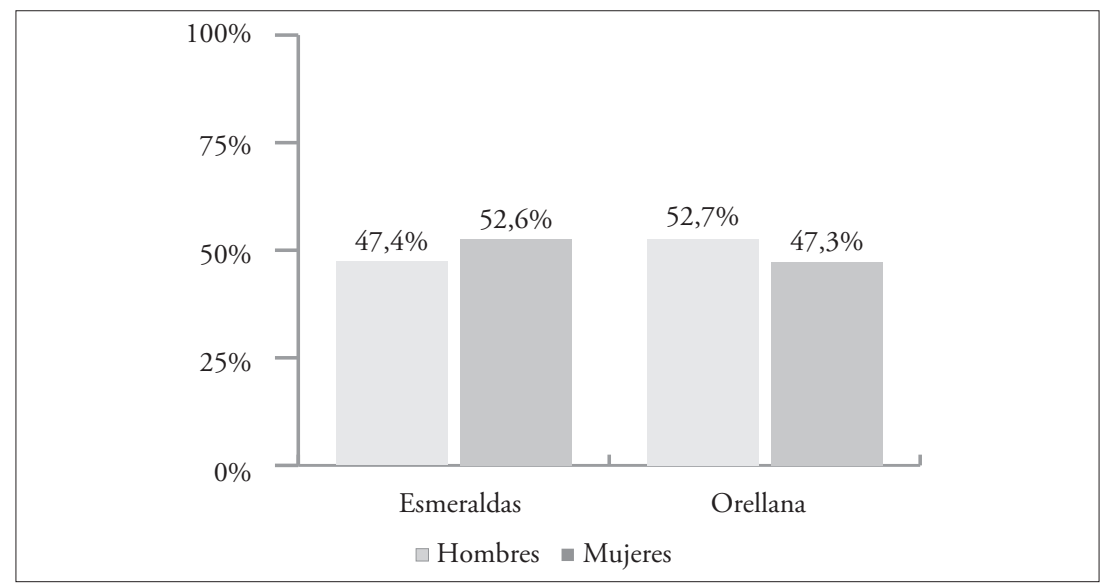

Fuente: CNE, Elecciones 2014

Elaboración: P. Jaramillo

Los autores, en su investigación sobre las presidenciales de 2010 donde se eligió a Dilma Roussef, reafirmaron dos hechos ya conocidos: "hombres y mujeres votan de manera diferente" pero "las mujeres no votan más a mujeres solamente por ser mujeres". 
Gráfico 15.

Sufragantes según sexo que votaron por las candidatas a alcaldesas en Catamayo, Durán y Fco. de Orellana

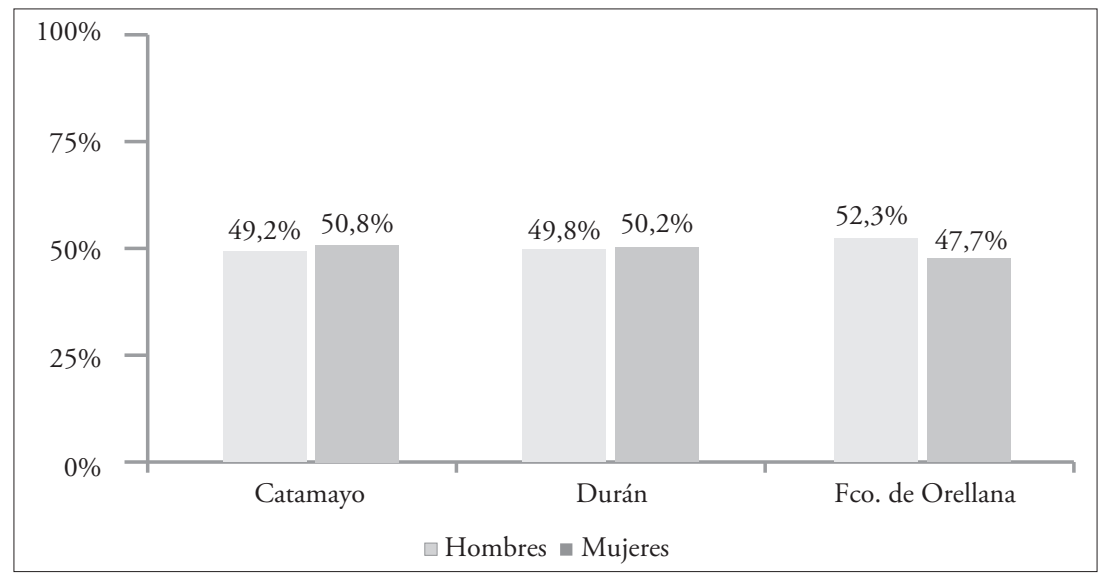

Fuente: CNE, Elecciones 2014

Elaboración: P. Jaramillo

Hay que considerar, por lo demás, que los porcentajes de mujeres que votaron por las prefectas electas en Esmeraldas y Orellana, son superiores al porcentaje de mujeres sufragantes en cada provincia: en Esmeraldas, $52,6 \%$ de mujeres votaron por la ganadora, frente a un 50,9\% de sufragantes femeninas; en Orellana, una de las provincias con menor porcentaje de mujeres electoras y sufragantes debido a la mayor presencia de hombres entre su población, un 47,3\% de mujeres votaron por la electa, de cara al 47,1\%, de mujeres sufragantes en la provincia.

\section{Conclusiones}

Uno de los desafíos del país en la etapa posconstituyente es avanzar en la concreción de derechos y garantías. La igualdad, concretada a nivel de la esfera electoral como derecho de las mujeres a la paridad, tanto en la candidatización como en la elección de las dignidades de representación y gobierno, viene topándose con una serie de problemas para su 
viabilización. El análisis de los resultados de las elecciones seccionales de febrero de 2014 arroja la luz acerca de algunos mecanismos electorales que parecen tener alta incidencia en las oportunidades de participación política de las mujeres en pie de igualdad.

Los datos muestran que, pese a las normas constitucionales y legales que garantizan la igualdad, la paridad no se cumple en la candidatización femenina. Una diferencia de casi 16 puntos entre candidatos hombres y mujeres revela la existencia de una notable brecha en la entrada del proceso electoral. Las brechas más significativas, con más de 70 puntos de diferencia, ocurrieron en la candidatización para los cargos de alcaldias y prefecturas.

Debido al primado de hombres en el encabezado de las candidaturas a prefecto/viceprefecto, el porcentaje de mujeres candidatizadas a viceprefectas constituyó, de lejos, el mayor a nivel local, aunque por déficit en la candidatización de mujeres a prefectas. En el caso de las alcaldías que no contemplan la nominación de candidaturas en binomio, este fenómeno no se produce, colocándola como la más desigual de las dignidades locales de elección. Los porcentajes de candidatización fueron más equitativos en las dignidades pluripersonales, superando el cuarenta por ciento en ambos casos. En calidad de suplentes, las mujeres fueron mayoría en todos las candidaturas a cargos plurinominales, lo que pone en evidencia un escenario de subalternización de las mujeres en la participación electoral.

La mayor distancia frente a la paridad, proviene de la participación de solo una cuarta parte de mujeres como electas. Los resultados más bajos se obtuvieron en los ejecutivos municipales y provinciales, con porcentajes por debajo de los 10 puntos. Solo Esmeraldas y Orellana eligieron prefectas y apenas 16 municipios eligieron alcaldesas de un total de 221. Al mismo tiempo, el mejor desempeño en todas las dignidades electas fueron las 21 viceprefectas, debido a que fueron electas en binomio con los prefectos quienes monopolizaron el encabezamiento de listas para esta dignidad. 
Estos resultados tienen que ver con la heterogeneidad que existe en la forma de constituir las dignidades uninominales, la cual se realiza mediante dos modalidades diferentes. La primera es la modalidad uninominal en binomio con la que se elige el par prefecto - vice-prefecto, y a la cual se aplican las normas de paridad y alternancia. La segunda es la modalidad uninominal de las alcaldías, en la cual la aplicación de las normas de paridad y alternancia es nula.

Los datos iluminan la importancia del tamaño de las circunscripciones en las oportunidades de elección de mujeres en listas pluripersonales, en una relación directa: mientras mayor el tamaño de la circunscripción, mayores chances para ellas. Sin embargo también hablan de diferencias sensibles que podrían ser de orden cultural en la elección, en el mismo tipo de circunscripción, entre los ámbitos urbano y rural. Para el caso de las concejalas urbanas, en circunscripciones medianas y pares, la candidatización muestra igualdad de oportunidades con tasas iguales o cercanas a la paridad. De modo similar, la brecha entre mujeres y hombres en los resultados es sensiblemente menor con una diferencia de apenas $6,4 \%$. No ocurre lo mismo en las circunscripciones pequeñas e impares: en éstas, la brecha de candidatización oscila en torno a los diez puntos mientras los candidatos hombres consiguen ser electos en casi el setenta por ciento en estas circunscripciones. En las circunscripciones únicas, las brechas de género en la candidatización es aún más marcada, con porcentajes de candidatos oscilando en torno al noventa por ciento.

En el caso de las concejalías rurales, aunque mujeres y hombres registran paridad en la candidatización en las circunscripciones medianas y pares, las brechas en la elección son mucho mayores que a nivel urbano en las circunscripciones pares, donde los hombres superan a las mujeres electas con 41 puntos de diferencia. Por su parte, en las circunscripciones pequeñas e impares del ámbito rural municipal, la situación es en todo negativa para las mujeres: por un lado, la candidatización muestra brechas mayores que las del promedio nacional y que las registradas a nivel de las circunscripciones urbanas; por otro lado, los resultados 
favorecen a los hombres al menos con 50 puntos de diferencia. En las circunscripciones únicas para concejalías rurales, aunque se registra un porcentaje de candidaturas femeninas más alto en ocho puntos que las del nivel urbano, los hombres electos obtienen una representación mayor en más de 80 puntos que ellas.

Las estadísticas comprueban también que el encabezado de listas pluripersonales a nivel urbano y rural y tanto de listas pares como impares, es de control hegemónico masculino: más de setenta por ciento de hombres a nivel urbano y rural encabezan las listas pares, mientras más de ochenta por ciento de ellos encabezan listas impares a nivel rural. Aunque para este ensayo no se analizaron los resultados según género de las listas abiertas, una revisión de literatura abona la idea de que este tipo de listas fortalece la elección de candidatos hombres debido a que, en general, cuentan con mayor posicionamiento en el ámbito político y manejan recursos que les permiten alcanzar mayor proporción de votos, mientras las mujeres deben enfrentar un conjunto de desventajas en sus campañas, presiones en su tiempo derivadas de sus roles domésticos y públicos, y patrones culturales tradicionales que asocian a las mujeres con los espacios domésticos o privados. La existencia de listas cerradas, según se habría comprobado en varias experiencias, favorecería la elección de mujeres y si éstas se encuentran bloqueadas, es decir que los escaños son inamovibles, la probabilidad de que mujeres accedan a espacios de representación, aumentaría.

Estos resultados colocan en un plano central la necesidad de discutir una reforma relativa a cuatro de los componentes del sistema electoral vigente, que permita contar con mejores oportunidades para el logro de la paridad. El primero remite a la necesidad de una homogenización virtuosa de las modalidades de conformación de las dignidades uninominales, todas las cuales deberían tomar la forma de candidaturas en binomio --tanto a nivel local como nacional-- para garantizar la aplicación de la normativa de paridad y alternancia en ellas. El segundo se refiere al encabezado de listas impares, cuyas implicaciones negativas para la paridad tanto en la candidatización como en la elección podrían 
ser modificadas mediante un obligatorio encabezamiento femenino, tal como ha sido aprobado en el presente año en el hermano país de Bolivia. Con el tercero nos referimos a la necesidad de encontrar una nueva geometría electoral que favorezca el establecimiento de circunscripciones de mayor tamaño, como prometedoras de una mayor equidad para las mujeres, pero al mismo tiempo, enfatizar en políticas que motiven el cambio de patrones tradicionales de elección por género sobretodo en los ámbitos rurales y para las dignidades municipales y parroquiales, donde las mujeres vienen cumpliendo roles de liderazgo y compromiso comunitario de gran importancia que no están siendo reconocidos. El cuarto mecanismo es la propuesta de cambio hacia una modalidad de listas cerradas y bloqueadas que favorece una mayor elección de mujeres, en los mismos puestos en que han sido candidatizadas.

Esta propuesta de reforma normativa busca ajustar el sistema electoral vigente, como estrategia para garantizar la igualdad de género y su expresión concreta, la paridad, en la distribución del poder. 


\section{Bibliografía}

Ayala, A. (2008). Camino a la Igualdad Real, Derechos de las Ecuatorianas, Quito, Ecuador, Fundación Chuquiragua / Embajada Real de los Países Bajos.

Bastidas Redín, C. (2013). "Voto facultativo de jóvenes en Ecuador: una cuestión de confianza y expectativas sobre la democracia" en Instituto de la Democracia (IDE), Revista Democracias, Volumen I, Octubre - Diciembre de 2013, Quito, Ecuador, IDD.

Consejo Nacional Electoral (2014). Estadísticas, Resultados del Proceso Electoral 2014, archivo pdf. Quito, Ecuador.

Consejo Nacional Electoral (2014). Indicadores de participación política de la mujer ecuatoriana. Quito, Ecuador.

Cavenaghi, S. y Diniz Alves, J. (2012). "Quién vota a quién: un retrato de las intenciones de voto en las elecciones para presidente en septiembre de 2010" en Dinz Alves, José Eustaquio, Céli Regina Jardim Pinto y Fátima Jordao (eds.), Mujeres en las elecciones de 2010. Sao Paulo, Asociación Brasilera de Ciencia Política ABCP, Secretaría de Políticas para las Mujeres del Gobierno Federal de Brasil.

Cisneros Palacios, F. (2013). "De votos a escaños: un análisis de los efectos del sistema electoral ecuatoriano" en Instituto de la Democracia (IDE), Revista Democracias, Volumen I, Octubre - Diciembre de 2013, Quito, Ecuador, IDD.

Diniz Alves, J. (2012). “Diferencias sociales y de género en las intenciones de voto para presidente en 2010". En Diniz Alves, José Eustaquio, Celia Regina Jardim Pinto y Fatima Jordao, eds., Mujeres en las elecciones 2010, Sao Paulo, Asociación Brasileira de Ciencia Política, Gobierno Federal de Brasil, Secretaría de Política para las Mujeres.

Feitosa, F. (2012). "La participación política de las mujeres en las elecciones 2010: panorama general de candidatos y electos”. En Diniz Alves, José Eustaquio, Celia Regina Jardim Pinto y Fatima Jordao, eds., Mujeres en las elecciones 2010, Sao Paulo, Asociación Brasileira de Ciencia Política, Gobierno Federal de Brasil, Secretaría de Política para las Mujeres. 
Gil Martín, F. (2011). Encuadre de la justicia y la esfera pública transnacional. Una aproximación a la teoría crítica de Nancy Fraser. Eikasia. Revista de Filosofía, año V, No. 39. http://www.revistadefilosofia.com Recuperado en http://revistadefilosofia.com/39-05.pdf Goetschel, A. \& Chiriboga, L. (2009). Relconstruyendo historias de mujeres ecuatorianas, Quito, Ecuador, CDT, AECID, Embajada de España.

Goyes, S. (2013). "La paridad ¿un camino a la igualdad? Análisis de las elecciones 2013” en Instituto de la Democracia, Revista Democracias, Volumen I, Octubre - Diciembre de 2013, Quito, Ecuador, IDD. (2008) De la Ley de Cuotas a la Paridad, documento borrador, Quito, archivo de Word.

Instituto Andaluz de la Mujer (s.f.) Indicadores de Género. Recuperado en http:/www.juntadeandalucia.es/institutodelamujer/ugen/ modulos/Indicadores/bgenero.html

Instituto de la Democracia, (s.f.). Elecciones Ecuador 2014. El sistema electoral y las nuevas circunscripciones electorales. Quito, Ecuador.

Lombardo, E. (2008). "Desigualdad de género en la política: un análisis de los marcos interpretativos en España y en la Unión Europea”, España, Universidad Complutense de Madrid, Revista Española de Ciencia Política, Vol. No. 18. Recuperado en: http://pendientedemigracion.ucm.es/info/target/Art\%20Chs\%20ES/ArtPolESUE_ RECP_08ES.pdf

Matos, M. y Brito Pinheiro, M. (2012). “Dilemas del conservadorismo político y del tradicionalismo de género en el proceso de 2010: el electorado brasileño y sus percepciones”. En Diniz Alves, José Eustaquio, Celia Regina Jardim Pinto y Fatima Jordao, eds., Mujeres en las elecciones 2010, Sao Paulo, Asociación Brasileira de Ciencia Política, Gobierno Federal de Brasil, Secretaría de Política para las Mujeres.

Nohlen, D. (2012). Gramática de los sistemas electorales. Una introducción a la ingeniería de la representación. Quito, IDD.

Olea, C. (2008). Apuntes para Ser y Hacer, proyecto KIC, Cotidiano Mujer No44, Montevideo, Uruguay. 
Rojo, C., Prieto, M., Sanchís, N., Rosero, R., North, L., Verdesoto, L. (1984). Mujer y Elecciones. Análisis del Voto Femenino en Quito. Quito, Ecuador. ILDIS.

Rosero, R., Vela M., y Reyes, A. (2000). De las demandas a los derechos: las mujeres en la Constituyente de 1998, Quito, Foro Permanente de la Mujer Ecuatoriana - CONAMU, Embajada de los Países Bajos.

Tribunal Supremo Electoral de Bolivia TSE (2014). Boletín Informativo Elecciones Generales 2014 en Democracia Intercultural. La Paz, Bolivia.

Vega Ugalde, S. (2004). "La cuota electoral de las mujeres: elementos para un balance”, en María Fernanda Cañete (comp.) Reflexiones sobre mujer y politica, Quito, Ecuador, CEDIME - Abya Yala.

\section{Normativa y documentos oficiales}

Constitución de la República del Ecuador (2008). Asamblea Constituyente. Ciudad Alfaro.

Ley Orgánica Electoral y de Organizaciones Políticas de la República del Ecuador, Código de la Democracia (2009). Asamblea Nacional. Quito: Suplemento R.O. 578 del 27 abril. 